\title{
La revelación de la razón: Max Weber y Franz Rosenzweig
}

\section{The Revelation of Reason: Max Weber and Franz Rosenzweig}

\author{
Eugenio Muinelo PaZ \\ Universidad Nacional de Educación a Distancia \\ emuinelopaz@gmail.com
}

Recibido: $10 / 05 / 2014$

Aceptado: 15/12/2014

\section{Resumen}

Partiendo de cómo los dos autores tratados se sitúan críticamente ante Hegel, se expone en primer lugar la cuestión del abandono de la filosofía de la historia. El agotamiento de la ontoteología histórica hegeliana impuso la necesidad de buscar nuevos modos de abordar la historia, más allá de la identificación panlogista de realidad y concepto. Surgió así con Weber y Rosenzweig un empirismo de la historia dispuesto a acoger a posteriori los datos del proceso de racionalización. Había que atender por tanto a lo que ponía en marcha, desde su afuera, a la propia razón. Y ello ya no era posible con la mera visión histórica, sino transitando hacia lo metahistórico y comprobando la tensión ineliminable que entre este plano y el histórico tuvo que generarse. Esto desembocó en la centralidad que ostenta, en los análisis de ambos, el estudio del judaísmo.

Palabras clave: filosofía de la historia, emanatismo, racionalización, metahistoricidad, judaísmo.

\begin{abstract}
The point of departure is how both of the authors criticize Hegel and leave philosophy of history. The exhaustion of Hegel's historical ontotheology set the task of searching for new ways to deal with history beyond panlogistic identification between reality and concept. So emerged an empiricism of history, which was opened to receive a posteriori the facts of the process of rationalization. Great attention was paid to what set reason in motion from outside itself. It wasn't
\end{abstract}


possible from a mere historical point of view, but only through the passage to metahistoricity. Its tensions with historicity gave them sufficient grounds to focuse their studies on judaism.

Keywords: philosophy of history, emanatism, rationalization, metahistoricity, judaism.

\section{De la razón de la historia a la historia de la razón}

Se tratará en lo que sigue de trazar la genealogía de una cierta recepción crítica de Hegel, pues cada uno de los autores que nos acompañarán comparten un destino, que no es otro que el de la filosofía posthegeliana: contra la parusía del saber consumado en que la filo-sofía se resuelve, reivindican, tanto Max Weber como Franz Rosenzweig, una apertura radical a la facticidad, al trabajo infinito de la historia, a esa "incurable herida de la vida", cantada por Nelly Sachs, no susceptible de ulterior suturación conceptual ${ }^{1}$. Dicho rápida y concisamente: en ellos se opera el tránsito de la filosofía de la historia a la filosofía histórica. Perseguiremos, por tanto, siempre el mismo gesto: renunciar a la captación (y posterior justificación o teodicea más o menos subrepticia) del hecho histórico en su necesidad, de la razón en la historia, con vistas a explorar el carácter constitutivamente histórico (y esto significará aquí: abierto, inclausurable) de la propia razón, del sistema. Interpreto este giro, expresado en el quiasmo con que intitulamos estas consideraciones preliminares, como la verdadera clave para la comprensión del nuevo eón filosófico que se inaugura post Hegel mortuum.

No pretendo en ningún caso ofrecer aquí una visión sinóptica de esa realidad multiforme y poliédrica que es el posthegelianismo, de su génesis y de su estructura. Me circunscribiré, pues, a las dos figuras inmensas mentadas en las que, en profunda afinidad electiva, se revelan muy manifiestamente estas aporías que atraviesan la segunda mitad del siglo XIX y los primeros e inciertos pasos del siglo Xx. Tanto uno como otro se cuentan entre los alumnos aventajados de Hegel, a quien leyeron con una agudísima conciencia de la necesidad de encontrar nuevas vías, un nuevo pensamiento tras el cumplimiento del arco filósofico que va "de Jonia a Jena"2. Una de las tesis medulares que aquí se defenderán es que la visión histórica de Weber y de Rosenzweig está condicionada de un modo directo por el hecho de que ambos fueron lectores críticos de Hegel.

\footnotetext{
1 "Aber die Heilung geschieht auf neuem Weg / denn niemals kann Eingang dasselbe wie Ausgang sein / wo Abschied und Wiederkunft / geschieden sind / durch die unheilbare Wunde des Lebens". Los versos pertenecen a Noch feiert Tod das Leben, contenido en Viaje a la transparencia. Obra poética completa, Madrid, Trotta, 2004.

${ }^{2}$ La expresión la debemos al ingenio del propio Rosenzweig. Aparece en Rosenzweig, La estrella de la redención, Salamanca, Sígueme, 1997, p. 52.
} 


\title{
2. El árbol de la ciencia: la epistemología histórica de Max Weber
}

Weber es sin duda un testimonio excepcional de la imposibilidad de toda filosofía de la historia ensayada desde coordenadas posthegelianas. Trataré de mostrar, en primer lugar, que su rechazo de toda teleología histórica, de toda suerte de hipóstasis a la manera del espíritu objetivo, no le hace caer en absoluto en un escepticismo epistemológico. Por lo menos, no en uno vulgar. En los textos relativos a la Wissenschaftslehre, hay innumerables y precisas indicaciones al respecto de cómo ha de afrontarse y realizarse un correcto estudio de la historia y de las ciencias sociales, acerca de cuyas pretensiones de verdad Weber no abrigaba sospecha alguna. Sí que las abrigaba, y con razón, acerca de toda presunta validez científica de determinados juicios de valor. Weber, que supo de la necesidad de valerse del mito cuando queremos tocar ciertas honduras, recurre, para describir esta constatación kantiana, a uno de nuestros mitos mayores, el contenido en el Génesis:

\begin{abstract}
"El destino de una época de cultura que ha comido del árbol de la ciencia consiste en tener que saber que podemos hallar el sentido del acaecer del mundo, no a partir del resultado de una investigación, por acabada que sea, sino siendo capaces de crearlo; que las «cosmovisiones» jamás pueden ser producto de un avance en el saber empírico, y que, por lo tanto, los ideales supremos que nos mueven con la máxima fuerza se abren camino, en todas las épocas, solo en la lucha con otros ideales, los cuales son tan sagrados para otras personas como para nosotros los nuestros"3.
\end{abstract}

Ante pasajes como este, la crítica de Leo Strauss se antoja casi obvia. Vendría a decir que Weber, aun reconociendo que toda praxis hunde sus raíces en la fe, apostó por la ciencia por considerarla el destino de la Modernidad ${ }^{4}$. De ahí, extrae la consecuencia, a mi entender demasiado precipitada, de que Weber se hizo cómplice de un relativismo desesperado, abandonado a la insolubilidad racional del conflicto ético-político. La crítica es obvia, antes que nada, porque el propio Weber asentiría a la premisa mayor. Nosotros, los hijos de Adán, tenemos que trabajar en el conocimiento; ciertamente esa es nuestra fe. Una fe dolorosa y trágica. Ya no es la hegeliana que se complacía en la subsunción dialéctica de la realidad en el concepto. Contra ella, Weber persigue una acotación rigurosa e implacable de la función legítima del saber, que no sería sino responder a la "necesidad de ordenar conceptualmente la realidad empírica de un modo que pretenda validez como

\footnotetext{
${ }^{3}$ Weber, M., "La «objetividad» cognoscitiva de la ciencia social y de la política social”, en Ensayos sobre metodología sociológica, Buenos Aires, Amorrortu, 1973, p. 46.

${ }^{4}$ Cf. Strauss, L., Derecho natural e historia, Barcelona, Círculo de Lectores, 2000, cap. II "El derecho natural y la diferencia entre actos y valores", especialmente las pp. 105-116.
} 
verdad empírica"5. Hasta ahí llega tal legitimidad, hasta la Umbildung típico-ideal (cuya orientación puede estar condicionada, Weber no lo niega, por un interés práctico) de la realidad en el concepto, Umbildung que, huelga decirlo, nunca será total, sino siempre parcial, pasada por el tamiz de la perspectividad. Esto parece olvidarlo, más o menos aviesamente, la vulgata weberiana que nos transmite Strauss, quien hace de Weber poco menos que un apologeta del cientificismo total. Ignora, pues, que si Weber es el gran teórico de la racionalización también lo es, en no menor medida, de su limitación, de su Grenzbestimmung. Lo real no es plenamente racionalizable ${ }^{6}$.

Tal sentido de la liminalidad distancia infinitamente a Weber de la órbita posthegeliana y, de hecho, le llevará a levantar acta de la crisis del historicismo, al cual Strauss indiscriminada e injustificadamente lo adscribe. La escuela histórica, nos dice Weber, bajo la apariencia de una crítica de la teleología hegeliana, perpetúa su emanatismo, su identificación panlogista de realidad y concepto. Escribe Weber en su artículo sobre Roscher, un discípulo de Ranke:

"Dentro de esta concepción «emanantista» de la naturaleza y validez de los conceptos «más elevados», es posible afirmar lógicamente que la relación entre concepto y realidad es pensable, por una parte, de modo rigurosamente racional, es decir, que la realidad es deducible descendiendo desde los conceptos generales, y que así, por otra parte, esta relación puede, a la vez, ser comprendida de manera totalmente intuitiva; ascendiendo hacia los conceptos, en efecto, la realidad no pierde ninguno de sus contenidos intuitivos. [...]

La forma de elaborar su propio esquema conceptual muestra, por tanto, que su posición, en principio, es distinta de la de Hegel, a pesar de que emplea ideas metafísicas que sólo podrían ser desarrolladas coherentemente dentro del esquema emanantista hegeliano. [...]

al devenir histórico, en cuanto objeto de nuestro conocimiento, le falta la necesidad, de forma que resta necesariamente un «horizonte inexplicable», y es precisamente tal horizonte lo que constituye el nexo de toda la realidad, puesto que de él dimana esta última"’.

Weber advierte de que el concepto de lo histórico que se maneja desde Hegel envuelve, cual lecho de Procusto, una muy problemática reductio ad unum. Esto es, el historicismo hereda la univocidad de la hegeliana exposición histórico-uni-

\footnotetext{
${ }^{5}$ Weber, M., "La «objetividad»...", en ibidem, p. 47.

${ }^{6}$ Un buen contrapunto a la lectura straussiana puede obtenerse del estudio: Schluchter, W., Religion und Lebensführung, Frankfurt am Main, Suhrkamp, 1988, v. I, pp. 50-51.

${ }^{7}$ Weber, M., "Roscher y Knies y los problemas lógicos de la Escuela Histórica de Economía”, en El problema de la irracionalidad en las ciencias sociales, Madrid, Tecnos, 1985, pp. 20-25.
} 
versal, aun cuando cree estar diversificándola. Así, el vacío dejado por la especulación histórica y sus gigantescas construcciones metafísicas se ve reemplazado por al afán, casi naturalista, de captar ciertas "leyes" de la historia conforme a las cuales se rigen los acontecimientos. Tal mecanización de la vida histórica le resulta a Weber, en este punto atento lector de Dilthey, simplemente intolerable. No hay para Weber ningún trasfondo ignoto que haya que postular como origen inaccesible de las leyes descriptibles en la historia. Para Weber, la sola idea de una legalidad absoluta, en cuya determinación se cifra todo el empeño del historiador, es insensata. Cierto que hay regularidades y leyes, mas estas son meramente hipóteticas y su función se restringe a la de ser un medio cognoscitivo, en el cual no se agota en absoluto el conocimiento de los fenómenos históricos. De ser así, retornaríamos al fetichismo del dato, a la historia anticuaria obsesionada por la tarea interminable, digna de Sísifo, de tener noticia de todo y de fijarla en un registro. Nietzsche, inspirador más o menos confesado de más de una intuición weberiana, ya había combatido con eficacia, en la segunda de sus Consideraciones intempestivas, este tipo de historia por sus muy nocivas consecuencias para la vida. Para Weber, una epistemología histórica que haya pasado verdaderamente por el fuego del purgatorio nietzscheano tiene que enfrentarse sin rodeos, urgente e ineludiblemente, a la pregunta de qué queremos conocer.

"Ahora bien, qué es lo significativo para nosotros es algo que ninguna investigación «sin supuestos» de lo empíricamente dado puede discernir; antes al contrario, su determinación es prerrequisito para que algo llegue a ser objeto de investigación. Lo significativo no coincide, naturalemente, en cuanto tal, con ninguna ley, y, por cierto, tanto menos cuanto más general sea aquella. En efecto, la significación específica que un elemento de la realidad tiene para nosotros no se encuentra en aquellas relaciones que comparte con muchos otros fenómenos". ${ }^{8}$

La crítica weberiana del historicismo viene propiciada, como puede verse, por una extremada fidelidad a los descubrimientos nietzscheanos: por una parte, contra la veta positivista de la escuela histórica, la negación de una ciencia sin presupuestos; por otra, contra la presunta transparencia de la realidad al concepto, intrínseca a su ascendencia hegeliana, la afirmación de la opacidad de los instintos que impelen al conocimiento. Recordemos lo que se dice en Wissenschaft als Beruf cuando, tras hablar de la especialización como destino de la ciencia, Weber sentencia taxativamente, subvirtiendo el prejuicio de la frialdad del científico, que "nada tiene valor para el hombre en cuanto hombre si no puede hacerlo con pasión". Aunque el científico no se aperciba de ello, lo mueve una voluntad, que es la que

\footnotetext{
${ }^{8}$ Weber, M., "La «objetividad»...", en ibidem, p. 66.

${ }^{9}$ Weber, M., "La ciencia como vocación”, en El político y el cientifico, Madrid, Alianza, 1972, p. 192.
} 
dirige su interés hacia tal y cual ámbito y no a otros. Ello no equivale sin más a que las verdades sean ilusiones de las cuales hemos olvidado que lo son; pero, desde luego, tampoco estamos muy lejos de esa operación quirúrgica, de afilado bisturí, que llamamos genealogía.

Cabe preguntar: ¿qué nos impide hacer de Weber un puro nietzscheano?, ¿es su proyecto de visibilización de la indeterminabilidad científica de los patrones científicos identificable tout court con la crítica de Nietzsche ${ }^{10}$ ? En parte sí y en parte no. Si bien es cierto que Weber está imbuido hasta la médula de su pathos, tampoco puede decirse, sin faltar a la verdad, que repitiese exactamente su gesto. Weber no quiere despedirse abruptamente de Hegel, evadiéndose en las alturas del solitario y escribiendo libros para todos y para nadie. Weber quiere recoger el testigo de Hegel, afrotando el reto legado por él mediante el trabajo infinito de la razón. Entre la racionalización integral y apriorística de la realidad histórica y la reducción de todo acontecimiento a mera forma de expresión de la voluntad de poder hay un camino medio que es precisamente el weberiano. En este sentido, suscribimos la observación de Pierre Bouretz, para quien la especificidad de la crítica weberiana del historicismo reside en su rechazo a la "evacuación completa del principio de razón"11 del cerco de lo histórico.

Estas consideraciones nos llevan directamente al núcleo de la polémica weberiana. La historia no es ni plenamente inteligible ni plenamente ininteligible. Con vistas a sortear ambos extremos, Weber propone que la historia posee una cierta inteligibilidad, pero que dicha inteligibilidad ha de ser construida típico-idealmente sin llegar nunca a una reconstrucción total. La formación de tipos ideales es, por ende, un procedimiento decididamente antihegeliano: parte de un fragmento de la realidad para regresar a la totalidad de la misma y esclarecer su inserción de aquél en ésta. No parten de la totalidad de la realidad histórica para, desde ella, enjuiciar lo que dentro de ella es posible o no. Esto es precisamente lo que Weber le achaca a Eduard Meyer ${ }^{12}$. En realidad, en toda esta cuestión, como el propio Weber reconoce, se trata de un cierto regreso a Kant, quien ya había advertido avant la lettre

\footnotetext{
${ }^{10}$ Para una lectura matizada y prudente de la relación Nietzsche-Weber, cf. Löwith, K., Max Weber y Karl Marx, Barcelona, Gedisa, 2007, especialmente pp. 42-60. Una vez puesto de relieve que ambos comparten una conciencia insobornable de la fundamentación extracientífica de lo axiológico, Löwith especifica que lo propio del proyecto weberiano es que, partiendo de la ruptura genealógica, se aventura en una ulterior "síntesis teleológica de racionalidad y libertad". Y ahí, naturalmente, ya no sigue a Nietzsche, a quien poco o nada podía interesar una historia de la razón.

${ }^{11}$ Bouretz, P., Le promesses du monde. Philosophie de Max Weber, Paris, Gallimard, 1996, p. 42.

${ }^{12}$ Cf. Weber, M., "Estudios críticos sobre la lógica de las ciencias de la cultura", en Ensayos de metodología sociológica, op. cit., p. 171: "nosotros aislamos mediante abstracción una parte de las «condiciones» previamente halladas en la «tela» del acontecer y la convertimos en objeto de «juicios de posibilidad», a fin de obtener de ese modo, mediante la ayuda de reglas de experiencia, una comprensión de la «significación» causal de los elementos singulares del acaecer. A fin de penetrar acabadamente los nexos causales reales, construimos nexos irreales".
} 
de la vacuidad de un concepto que no se pliegue ante la presión de lo real, sino que, por el contrario, se tenga a sí mismo por el Alfa y Omega del conocimiento. Es por ello que para el historiador kantiano que Weber tiene en mente:

"la relación entre concepto y labor historiográfica se invertirá: [...] los conceptos no son ya fin sino medio con miras al conocimiento de las conexiones significativas desde puntos de vista individuales: precisamente porque el contenido de los conceptos históricos es necesariamente mudable, deben ser formulados en cada caso de manera necesariamente precisa. Quien tal piense exigirá sólo que en la aplicación de esos conceptos se recuerde cuidadosamente su carácter de cuadros conceptuales ideales, y que no se confundan tipo ideal y realidad histórica. Puesto que no puede pensarse realmente en conceptos históricos definitivos como meta general, a causa del cambio inevitable de las ideas de valor rectoras, aquel considerará que el hecho mismo de que se formen conceptos precisos y unívocos con relación al punto de vista singular, rector en cada caso, proporciona la posibilidad de volver conscientes, de manera clara, los límites de su validez"13.

Puede haber, en definitiva, una "ciencia de la realidad" en sentido estricto, mas no omnicomprensivo. Ello se debe a que tal inteligibilidad no proviene de ningún vórtice supremo hacia el que todo hecho o acción histórica, aun a despecho de su "actor", converge. De ser así, una vez instalados en esa cumbre, bastaría con una retrospección especulativa que nos permitiría juzgar en qué medida cada uno de los implicados en la intrincada trama de la historia universal han contribuido a la realización del Espíritu. La ciencia weberiana de la realidad nos induce, por el contrario, a aproximarnos a lo histórico, ya que fruto de la libertad humana, en su constitutiva e irreductible indeterminación; aproximación que será eo ipso asintótica, pues tenderá a una delimitación cada vez más nítida, mas interminable, de lo racional en la acción humana y se abrirá, en última instancia, a una teoría de la razón siempre por hacer ${ }^{14}$.

\footnotetext{
${ }^{13}$ Weber, M., "La objetividad...", en ibidem, p. 96.

${ }^{14}$ Vemos cuánto se acerca el concepto weberiano de lo histórico al que encontramos en aquellas tensas páginas en las que el joven Schelling busca darles una configuración sistemática a los escritos kantianos sobre la historia. Nos referimos al Sistema del idealismo trascendental (Barcelona, Anthropos, 2005, pp. 387-388), en donde leemos: “...es evidente que la historia no existe ni con absoluta legalidad ni tampoco con libertad absoluta, sino que sólo se da allí donde se realiza un único ideal bajo una infinidad de desviaciones [...]”. De ahí se sigue “...que absolutamente nada de lo que sucede según un mecanismo determinado o tiene su teoría a priori es objeto de la historia. Teoría e historia son totalmente opuestas. El hombre tiene historia sólo porque lo que hará no se puede calcular de antemano por ninguna teoría".
} 


\section{Del pecado al mundo. Interpretación weberiana del judaísmo}

Con Weber no estamos, pues, ante una claudicación de la razón, sino más bien ante la elaboración de $s u$ historia, sólo accesible a posteriori. Desde esta opción difícil quiso emprender su magno proyecto comparativo Ahora bien, ¿cuál es el objeto de una tal historia de la razón? Ni más ni menos que el tema hegeliano por excelencia: la cuestión histórico-universal y la significación única, singular de Occidente en ella. Esto lo sabemos desde el mismísimo incipit de la "Introducción" a La ética protestante ${ }^{15}$. No se nos dice allí, no mucho menos, que la Weltgeschichte sea Weltgericht, mas ello no es óbice a la admisión de una dimensión universal del análisis histórico. Si la obra weberiana sigue interpelándonos hoy tan acuciantemente, ello se debe a que Weber fue, entre otras muchas cosas, un pensador del mundo, de la "mundialidad" del mundo. Todo lo que un cierto discurso sociológico contemporáneo designa, no sin cierta vaguedad, como "secularización" y "globalización" no sería, para Weber, sino un modo imperfecto de nombrar lo que él gustaba de llamar proceso de racionalización. Este solo es lo que nos permite unificar y conferir algo así como una inteligibilidad al de lo contrario incontrolable magma de los acontecimientos históricos. Sólo por la racionalización hay historia del mundo, hay un saeculum, hay, como escribiría Rosenzweig, un globus ${ }^{16}$. Y para Weber, a diferencia de una cierta literatura crepuscular de cuño splengleriano, no hay duda de que fue en Occidente, y sólo en Occidente, que se inició, para jamás cesar, esta vía regia de la racionalización llamada a acoger en su seno todos los modos no occidentales de vida. Esto es lo que quiere decir, simplemente, que sólo en Occidente es concebible "una dirección evolutiva de alcance y validez universales"17. Quien, esgrimiendo argumentos impertinentes, pretenda hacer de Weber una suerte de apóstol de la superioridad occidental, ha de leer, y meditar detenidamente lo que allí se dice, el escrito sobre la Wertfreiheit ${ }^{18}$. La racionalidad formal del ethos occidental es una constatación histórica, en modo alguno un juicio de valor. La gran obsesión weberiana será la indagación de las condiciones de posibilidad de la génesis de tal ethos.

Puede resultar conveniente, antes de proseguir, apuntar una palabra respecto a la consabida crítica weberiana del materialismo histórico: Weber persiguió completar la tesis marxista, no anularla. Idea e interés en su acción recíproca son, en consecuencia, el verdadero objeto de estudio de la sociología, pues "las «imágenes

\footnotetext{
${ }^{15}$ Weber, M., Ensayos sobre sociología de la religión, v. I, Madrid, Taurus, 1998, p. 11.

${ }^{16}$ Así, Globus, se intitula un escrito geopolítico fundamental de Rosenzweig, cuya traducción, al cuidado de Roberto Navarrete, está en prensa como parte del volumen Escritos sobre la guerra, que verá la luz en la editorial Sígueme.

${ }^{17}$ Weber, M., ibidem.

${ }^{18}$ Weber, M., "El sentido de la «neutralidad valorativa» de las ciencias sociológicas y económicas", en Ensayos sobre metodología sociológica, op. cit., pp. 222-269.
} 
del mundo» creadas por las «ideas» han determinado, con gran frecuencia, como guardaagujas, los raíles en los que la acción se ve empujada por la dinámica de los intereses" $"$. De estas líneas se colige con ineluctable necesidad por qué el grueso de la labor weberiana se tuvo que volcar en una sociología comparada de la religión, pues en la religión percibe Weber un tipo singularísimo de acción comunitaria en el que se imbrican de modo paradigmático representaciones y efectos prácticos.

En todo lo que sigue defenderé la tesis de que la clave de bóveda de todo el edificio histórico weberiano está constituida por su ensayo sobre el judaísmo antiguo, lo cual, a primera vista, no parece una tesis demasiado novedosa. Efectivamente, que la irrupción profética en Israel ejemplifica de un modo notable la dinámica de la Entzauberung y la desactivación irreversible de las técnicas mágicas de salvación raya en lo tópico. Pero la mención no suele pasar de ahí; no se le suele conceder la significación central que yo aquí le atribuiré, sino la meramente tangencial, casi se podría decir fortuita, de haber iniciado un proceso que luego se traslada a otras coordenadas. Desde la perspectiva aquí adoptada, en cambio, argüiré que el trabajo sobre el judaísmo no es un tomo más dentro de los ensayos de sociología de la religión, sino el texto axial en torno al cual todos los demás orbitan y desde el cual adquieren su pleno sentido.

\section{La Alianza: desterritorialización y racionalización}

Hay una racionalidad mágica, mas ésta es únicamente zweckrationell, pragmática: asegura la estabilidad del orden conocido. Es natural, por lo mismo, que la destrucción de la magia genere un momento de angustia: se resquebraja todo lo que hasta entonces era inconmovible, se disipa la placentera atmósfera del éter mágico. Esta auténtica Umwertung es la innovación radical que introduce la Alianza veterotestamentaria, la berit, contraída por Israel para con Yahveh, experiencia fundacional cuyo testimonio vibrante nos transmite cada una de las páginas de la Toráh. La noción de Alianza constituye la culminación de una "progresiva teologización del Derecho", cuya peculiaridad reside "ante todo en la extensión extraordinariamente amplia de la berît religiosa en tanto fundamento real (o artificioso) de las más variadas relaciones jurídicas y morales" ${ }^{20}$. Tal sentido de la Alianza, asegura Weber, podemos detectarlo ya con suma plausibilidad desde los tiempos anfictiónicos. De

\footnotetext{
${ }^{19}$ Weber, M., "Introducción a La ética económica de las religiones universales", en Ensayos sobre sociología de la religión, v. I, op. cit., p. 247.

${ }^{20}$ Weber, M., Ensayos sobre sociología de la religión, v. III. El judaísmo antiguo, Madrid, Taurus, 1998, pp. 98-100. Podría remitirse aquí, forzando un cierto quiasmo, a la inversión del teorema schmittiano efectuada por Jan Assmann, quien buscó rastrear, deteniéndose con atención en el caso de Israel, la raíz política de algunos conceptos teológicos. Cf. Assmann, J., Herrschaft und Heil. Politische Theologie in Altägypten, Israel und Europa, München-Wien, Carl Canser, 2000, p. 29.
} 
hecho, Weber subrayará con enfásis la extremada relevancia de una configuración comunitaria en forma de confederación de tribus vinculadas única y exclusivamente por una Alianza sellada con Dios ${ }^{21}$; con un Dios, por ende, que ya no es el propio de esta o aquella tribu, sino el de todas ellas, las cuales se ven así unificadas, preservando no obstante sus diferencias de raíz étnica, mediante un singular sentimiento de confraternidad nacido de la comunidad de culto y de sacerdocio. Las barreras étnicotribales fueron consecuentemente integradas en un horizonte más amplio, Israel, que "no era una denominación tribal, sino el nombre de una asociación, precisamente de una confederación cúltica" 2 .

La Alianza es, pues, la fuente de todas estas peculiaridades. Y de muchas más. Es sólo en virtud de ella que se hizo posible un concepto de Dios y de sus relaciones con el hombre que, en opinión de Weber, fue el más poderoso agente de racionalización habido hasta entonces. La Alianza con Dios, con un Dios que ha querido de una manera puramente gratuita estar con su pueblo, y que, por consiguiente, puede también, a despecho de toda compensación sacrificial articulada sobre el $d o$ ut des, disolver esa alianza con motivo de la desobediencia de este; una Alianza de tal índole, decimos, imposibilita toda relación mágica y abre, además, una dimensión insospechada de temporalidad. La voluntad de Yahveh no es en modo alguno gestionable, no se puede manipular arbitrariamente en beneficio propio a través de un mecanismo de repetición; hay que hacerse en todo momento, sin certitudo salutis alguna (esto es, siempre en tensión hacia la donación de un acontecimiento que no se puede forzar), merecedor de su gracia ${ }^{23}$. Todo el Antiguo Testamento no sería en este sentido sino una historia de la Alianza y de sus incesantes renovaciones. La Alianza no es una adaptación al orden inmutable de la naturaleza decretado de una vez por siempre por cualesquiera divinidades. No, la Alianza crea un Derecho positivo susceptible de ser modificado de nuevo por la libre voluntad divina. Aquí el Dios no está bajo la necesidad, llamése esta como se quiera: fatum, ananké, ptah, tao o dharma.

La renovación de la Alianza fue sin duda uno de los aspectos veterotestamentarios que más atrajeron a Weber. Que la Alianza con el Dios de la promesa, la cual entrañaba unas obligaciones muy estrictas y específicas, se pudiera quebrar por mor de la "deserción respecto de Yahveh"24: este le parecía a Weber el punto decisivo,

\footnotetext{
${ }^{21}$ Como en tantas otras cuestiones, aflora en este punto la complementariedad de Weber con Freud, cuyo Moisés y la religión monoteista pivota también en torno a la Alianza con el Ausente.

${ }^{22}$ Op. cit., p. 107.

${ }^{23}$ Hesed, término vertido al castellano como "gracia" o "misericordia" y que aparece íntimamente ligado a la Alianza; véase, por ejemplo, Dt, 7, 9.

${ }^{24}$ Op. cit., p. 144: "Las promesas del pueblo servían de base a su obligación especial y permanente para con el dios, mientras que las promesas ofrecidas por éste como contrapartida lo convertían para Israel en un Dios de la promesa en un sentido tan eminente como ningún otro dios conocido de cualquier país en toda la historia universal. Ésta es la prístina posición de la tradición. Ella constituye el fundamento
} 
preludio de toda la revolución profética. La imposición de una misión particular derivada de la idea de elección permitió una ampliación muy notable, sin precedentes, de la conciencia histórica, dado que el Dios de la confederación tenía que mostrarse también en las interferencias con los otros pueblos, con los goyim. Dios, al no encontrarse con Israel en ningún tipo de conexión directa o natural relacionada con el linaje, la tierra, etc., no tenía con su pueblo más que una relación ética. De ahí se sigue que las desgracias que le sobrevengan hayan de deberse a alguna falta suya, a una irresponsabilidad para con la promesa divina. El truncamiento de la misma por los pecados de Israel lo efectúa Yahveh mediante los asedios de las gentes, que quedan incorporadas así en un marco histórico-universal.

Es relevante para entender la inserción de los otros pueblos en el destino de Israel recalcar el hecho de que ya en época anfictiónica observamos ciertas disposiciones que podían conducir a esa inclusividad. Sin dejar de ser correcta, la línea evolutiva trazada esquemáticamente por Weber en el pasaje recién aducido es, sin embargo, matizable, como el propio Weber muestra al repetirnos infatigablemente que Yahveh no es originariamente un dios local. Se hace tal, en todo caso, en tiempos de la monarquía, y ni siquiera de un modo demasiado unívoco. Mas, en un principio, se trata de una deidad extraña, no conocida desde siempre por el pueblo. Yahveh se hace conocer a la confederación por iniciativa propia y en un momento dado. Antes de tal decisión, no está en una relación más estrecha con Israel que con cualquier otro pueblo. Sólo esta ausencia de vínculos naturales, insistimos, posibilita que las acciones de Yahveh puedan afectar también a otros pueblos. Los dioses de la tierra, los dioses locales, provocan la clausura de las sociedades en sí mismas, delimitando rígidamente lo propio y lo ajeno, o, más bien, absolutizando lo propio e ignorando lo ajeno. La elección por parte del "Dios lejano", bajo la apariencia de férreo exclusivismo, inaugura la posibilidad de pensarse en relación con el otro, pues sólo la Alianza inculca la conciencia de la propia condición de advenedizo, de extranjero en la tierra, que se comparte, aun a su pesar y aunque intenten negarlo, con todos los demás pueblos. Esa conciencia, insomne y vigilante, origina la santidad del pueblo santo.

\section{Profecia: ética, escatología y teodicea}

La profecía, tanto la pre- como la postexílica, continúa según Weber la línea iniciada con la sistematización ético-racional levítica de la Toráh, de la enseñanza divina, compendiada prodigiosamente en el Deuteronomio. El profeta, cierto es, se erige a título personal como emisario carismático del espíritu de Yahveh para exhortar al pueblo a obedecerle. No obstante, el presupuesto y el núcleo de

clarísimo del concepto, inexistente en parte alguna del mundo circundante de Israel, pero presupuesto ya en el Cántico de Débora, de la deserción respecto de Yahweh como un delito específicamente depravado". 
su mensaje no es sino la Toráh, de lo cual se derivan rasgos importantes: por una parte, que el profeta interpreta él mismo, a diferencia de la pitonisa y del médium extático, la palabra divina que recibe, dadas la racionalidad y la comprensibilidad de esta; por otra parte, y esto es lo que más interesa a Weber, su misión, aunque de raíz puramente religiosa, tiene una clara y evidente implicación política, motivo por el cual se vieron obligados a realizar su predicación en público, sin refugiarse en cenáculos o asociaciones esotéricas de virtuosi, como será habitual en la apocalíptica. La Toráh, tal y como los levitas la pergeñaron, es vinculante para todos y cada unos de los miembros del pueblo y, por ende, la interpelación profética se dirige a todos ellos.

La principal aportación de los profetas, que presupone la formación estatal, sería la elaboración de una teodicea. Sólo en una comunidad políticamente configurada y sobre cuyo futuro inminente se cierne una grave amenaza es posible que aparezca algo semejante. Para Weber lo admirable del pathos profético es que, en una tesitura semejante, proclama justo lo contrario de lo que naturalmente cabría esperar. La respuesta estereotipada, que encontramos tan a menudo en otras partes, sería lisa y llanamente que el Dios del pueblo ha fracasado y que los dioses extranjeros se han impuesto sobre él. El profeta protesta con vehemencia contra tales extravíos, lo cual le convierte en un personaje políticamente relevante, si bien, como queda dicho, ello de un modo únicamente secundario.

El desastre político, más que traicionar la impotencia de Yahveh, magnifica su gloria y soberanía; la profecía preexilíca es, casi en su integridad, profecía de infortunio, e imputa tal infortunio a las faltas del pueblo. A mi entender, Weber toca el nervio del asunto cuando afirma que tan sólo con la irrupción del complejo de ideas mesiánico se culmina la sublimación de la noción de pecado en una Gesinnungsethik o ética de convicción, cuya condición de posibilidad es precisamente la fe profética. El magno plan divino de salvación y perdición ofrece el marco propicio en que una tal ética puede formarse. Sólo interpretando el pecado, no como infracción de tal o cual precepto que puede compensarse de tal o cual manera, sino como causa de la perdición irremisible que sólo el arrepentimiento sincero, desinteresado, y la conversión a Dios pueden evitar; sólo así, decimos, se genera una indiferencia ante el mundo (que es más su puesta entre paréntesis que su rechazo; piénsese en el hos paulino y en su retoño moderno, el als ob kantiano) que es la condición sine qua non de una acción racional sustentada en una esperanza absoluta como a la que los profetas exhortan. En este sentido, la ética de convicción invocada por la parénesis profética "significa una tensión profunda respecto a las realidades del mundo". Ello se debe a que "rompe la estereotipación de la norma particular a favor de la relación total, «plena de sentido» del modo de llevar la vida respecto al fin religioso de salvación" 25 .

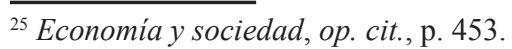


El pecado, perfectamente rememorable e imputable (siendo, por ende, algo de lo que cabe arrepentirse cabalmente), entendido como origen del sufrimiento y del mal cuya eliminación, en cooperación con Dios, le está encomendada al hombre; tal idea del pecado y de su futura superación colectiva, decimos, es el primer paso del proceso de racionalización. Es por ello que puede Weber sentenciar tras su colosal estudio sobre las religiosidades orientales:

\begin{abstract}
"No hubo ni una ética práctica ni un método de vida racionales que desde este jardín mágico de la vida toda llevase al «mundo». Ciertamente, se dio la oposición de lo divino y el «mundo» que históricamente condicionó en Occidente la constitución de esa sistematización unitaria de la conducta que habitualmente se denomina «personalidad ética». Pero en ningún lugar de Asia se trató de la oposición entre un dios ético y un poder del «pecado», del mal radical, que hubiera que superar por medio de la conducta activa en la vida" ${ }^{26}$.
\end{abstract}

Se entiende, pues, por qué el frontispicio del presente apartado reza: del pecado al mundo. En este tránsito cifra Weber el logro formidable del racionalismo religioso, alcanzado merced a una sistematización específica de la idea de redención ${ }^{27}$. Sólo el hombre situado ante la tarea de la redención, ante la redención como tarea, puede considerar el mundo como "material" de su obra. Sólo la profecía ética nacida en el seno del judaísmo pudo independizar al hombre del mundo sin desvincularlo de él. Sólo la profecía ética pudo, en definitiva, crear algo así como el mundo, abrir la dimensión de lo mundano y circunscribirla con nitidez, más alla de la unilateralidad de toda confuciana adaptación al y de toda ascética negación del mundo, en las cuales hombre y mundo están o bien indiscerniblemente integrados o bien irreconciliablemente separados. El mundo, como tal, sólo aparece en proporción a la tensión con que ante él se sitúa el hombre y esto sucedió de un modo eminente en el judaísmo.

Para despedirnos de Weber, digamos que su titánica labor, toda ella, no expresa sino esa "tensión hacia el mundo", cuyo origen adscribimos, siguiendo sus pasos, a la Erlösungsreligion. Hay un pasaje de la célebre Zwischenbetrachtung especialmente instructivo al respecto:

\footnotetext{
${ }^{26}$ Weber, M., La ética económica de las religiones universales II. Hinduismo y budismo, en Ensayos sobre sociología de la religión, v. II, Madrid, Taurus, 1998, p. 353.

${ }^{27} \mathrm{Cf}$. "Introducción a La ética económica de las religiones universales" en Ensayos sobre sociología de la religión, v. I, op. cit., pp. 246-247.
} 
"[La tensión con el mundo] se siguió del sentido de la redención y de la esencia de la doctrina profética de salvación con tanta mayor intensidad cuanto más evolucionaron sus principios hacia una ética racional, orientada hacia bienes religiosos internos como medios de salvación; [...] Efectivamente, la racionalización y consciente sublimación de las relaciones del hombre con las diversas esferas de posesión interna y externa, religiosa y mundana, de bienes condujo a que se hicieran conscientes en sus consecuencias las especificas legalidades internas de cada esfera en particular y a que entraran por ello en aquellas tensiones mutuas que estaban veladas a la ingenua relación originaria con el mundo exterior"28.

Elaboración racional de la distinción entre la legalidad específica de las diversas esferas de acción sin posibilidad de suprimirla mediante síntesis totalizante: así podríamos definir, en una sola frase, el tema weberiano por excelencia. Se ve, por tanto, dónde hunden sus raíces una sublimación por el conocimiento como la que encontramos en la sociología de Weber y su consiguiente reconocimiento de las tensiones ineliminables ( $\mathrm{si}$ acaso, pueden ser englobadas en un todo que infunda la ilusoria sensación de justificación; mas esta no es, como hemos visto y aún veremos, sino una argucia del idealismo). Llegados a este punto, anticipo que de lo que se tratará al hablar de Rosenzweig es de poner de manifiesto la perfecta complementariedad entre la descripción exotérica weberiana del despliegue histórico de la idea de redención como proceso de racionalización y esa recreación narrativa y esotérica (esto es, trabajada desde dentro) del mismo despliegue que es La estrella de la redención.

\section{Los años de aprendizaje de Franz Rosenzweig}

Rosenzweig parte, como Weber, de un enfrentamiento con Hegel. Escrito bajo la dirección de Friedrich Meinecke, su Hegel und der Staat constituye un verdadero hito dentro de los estudios hegelianos. Su objeto de estudio, bien definido, fue la significación, difícilmente exagerable, que para la historia política de Alemania tuvo el momento hegeliano con su peligro incesante: la apropiación de la filosofía históricopolítica de Hegel con vistas a justificar un craso nacionalismo político. Ahora bien, ¿secunda Rosenzweig por completo en sus escritos tempranos, tanto en el Hegel como en otros escritos menores, pasando por su correspondencia, la visión, digamos, conciliadora que abanderaba Meinecke? No me parece que ése sea en absoluto el caso. No considero, por ende, que la "conversión" rosenzweiguiana haya sido realmente tal, como tan a menudo, de un modo casi hagiográfico, se nos describe. Desde luego, hay constancia de que saludó Weltbürgertum und Nationalstaat con verdadero

\footnotetext{
${ }^{28}$ Weber, M., "Excurso. Teoría de los estadios y direcciones del rechazo religioso del mundo", en Ensayos sobre sociología de la religión, v. I, op. cit., p. 532.
} 
entusiasmo, manifestando con fervor su deseo de continuar la vía abierta por tan magnífica obra. Pero en el Hegel aparecen ya desafíos nuevos, fulgurantes, que, naturalmente, Meinecke no podía osar imaginar. Se trata, como vimos al hilo de Weber, de una revisión profunda del universalismo hegeliano, motivada paradójicamente no tanto porque Hegel estuviese equivocado, sino precisamente porque tenía razón. Hegel es para ambos, Rosenzweig y Weber, la expresión más acabada de una filosofía en la que los fundamentos últimos que determinan el mundo histórico vienen a la luz de la conciencia, inaugurando la posibilidad de que esta se reconozca en la realidad fáctica y la abrace satisfecha. Las Lecciones sobre filosofía de la historia universal, en conjunción con la Filosofía del derecho, no serían sino el testimonio de tales nupcias. Como intentaré hacer ver, en Rosenzweig encontramos un distanciamiento de esta visión histórica que no difiere sustancialmente del ejecutado por Weber.

Pero respondamos antes a la pregunta recién arrojada: ¿en qué se desmarca Rosenzweig de su maestro? ¿qué le llevó a convertirse, según el mismo se calificó, en un filósofo "inhabilitable" 29 , ajeno al ambiente académico alemán? Para no desviarnos excesivamente, indico muy esquemáticamente las líneas maestras de la recepción meineckeana de Hegel: perseguía ante todo presentar a un Hegel en que se pudiese apoyar sin demasiadas estridencias el proyecto de un Estado nacional animado por la idea, más o menos larvadamente imperial, de universalidad. Una cierta visión del Estado como realización definitiva de la Razón que mueve los hilos del teatro de la historia podía muy bien casar con todo esto. Meinecke no vio, y esta será la crítica central de Rosenzweig, que se trataba de una fachada que ocultaba, bajo el pretexto de una adaptación del ideal cosmopolita a la coyuntura estatal-nacional, una unilateral pulsión particularista, arraigada en una muy oscura noción de "voluntad nacional" cuyo cauce natural es el conflicto. Escrito ante el horror de la Gran Guerra (esto es, seis años después de terminado el libro), Rosenzweig podrá decir en el epílogo a Hegel y el Estado, asistido por poderosas razones, que hay un camino "de Hegel a Bismarck", camino que es precisamente el trazado por Meinecke, aunque éste no hubiese advertido lo que de distorsión del auténtico pensamiento hegeliano en él había $^{30}$. Rosenzweig no fue, pues, ni ingenuo ni simplista. Su crítica de Hegel no busca estigmatizarlo, sino comprender retrospectivamente las potencialidades que su filosofía, incluso a pesar suyo, albergaba y que se cristalizaron en la realidad histórica del momento. Rosenzweig, movido inicialmente, en la estela de la Ideengeschichte, por el "hambre de formas", tuvo que descubrir con la madurez que tal hambre era tantálica y que era preciso penetrar, para sortear el tormento infinito, en los intersticios de la historia. Mas ése es el tema del siguiente capítulo, no de este.

\footnotetext{
${ }^{29}$ Rosenzweig, F., "Carta a Meinecke” en Lo humano, lo divino y lo mundano, Buenos Aires, Araucaria, 2007, pp. 83-88.

${ }^{30}$ Cf. Rosenzweig, F., Hegel und der Staat, Aalen, Scientia, 1982 (sigue la paginación de la edición original de 1920), v. II, p. 244.
} 
Lo que más nos interesa ahora de Hegel es lo siguiente: el cristianismo introduce la Versöhnung en el mundo e inicia una nueva y definitiva época. El escrito sobre $L a$ Constitución de Alemania (1802) ya apunta en esa dirección. Se hace ver allí que la autonomización (saecularisatio en sentido institucional del término) del Estado no envuelve en modo alguno un proceso de descristianización, sino que, muy al contrario, conduce a la perfecta consumación del cristianismo y de su impulso a realizar la razón. Lo decisivo para Rosenzweig está en que de este modo se opera una identificación omnímoda entre historia de la religión e historia universal, pues el cristianismo clausura ambas. El cristianismo es, en su versión hegeliana, el único fenómeno histórico-universal que no tiene carácter episódico. El mundo europeo-germánico es el único en que ha podido gestarse un weltgeschichtliches Volk que, por muchas mutaciones a las que se vea sometido, perdurará por siempre en una evolución cada vez más perfecta hacia la completa libertad. Rosenzweig evoca muy agudamente el reino eterno de Daniel 7, 23.

Una filosofía histórico-política semejante sólo podía ver la luz en un siglo en el que, como en el XIX, imperó de un modo inusitado el principium individuationis. Precisamente Hegel es una respuesta a tal desmembramiento de las naciones europeas, a las que busca subsumir integrándolas en el destino cristiano-protestante, en la ecclesia invisibilis. Hegel quiere que en virtud del pleroma del proceso históricocristiano se imbriquen mutuamente Iglesia y Estado, que la religión suministre su poder de convicción (Gesinnung) al Estado y que el Estado contribuya, por su parte, a la exteriorización de lo interno, a la implantación laboriosa de la razón en la realidad, a la Verweltlichung de lo divino. El peligro obvio es la deificación del Estado. La sangrienta unificación alemana, se lamenta Rosenzweig sentidamente, fue una tal ofrenda sacrificial al nuevo Moloch.

\section{Historia y exterioridad}

\section{El nuevo pensamiento: de la lógica a la gramática}

Que una filosofía que se abra a la temporalidad y a la experiencia tenga que deponer la forma deductiva y adoptar la narrativa fue el gran hallazgo schellingiano al que Rosenzweig se adhirió con pasión. El pensamiento es intemporal y, en consecuencia, su pregunta por la totalidad la resuelve sin atender al hecho de que la realidad tiene sus tiempos. No los acontecimientos singulares, sino la realidad en bloc tiene su "pasado perpetuo" y su "futuro eterno"31. Tal es la lección indeleble que Rosenzweig extrae de las Weltalter. El Antiguo Pensamiento es la Lógica, cuya clausura circular constituye la más íntima esencia de esa racionalidad que

\footnotetext{
${ }^{31}$ Apretada y concisamente presenta Rosenzweig tales temas en esa suerte de prólogo rezagado a $\mathrm{La}$ estrella que es El nuevo pensamiento, Madrid, Visor, 1989.
} 
culmina en la síntesis idealista. El Nuevo Pensamiento es la Gramática, que presupone la apertura a la donación de lo que uno no sabe ni puede darse a sí mismo: la palabra y el tiempo. Una cierta excentricidad es, pues, el origen de esa "filosofía experiente" (erfahrende Philosophie) en que el Nuevo Pensamiento consiste. Sólo desde la ruptura de la estructura concéntrica de la totalidad se entiende esa ineludible protesta con que da comienzo La estrella de la redención: la muerte no es una nada, sino un algo, el Algo, lo ineliminable e inagotable. Como vimos hacia el final del tercer apartado, en Weber aparece ya el rechazo de la síntesis idealista por ilusoria, amén de por irrespetuosa para con la legitimidad diferencial de las diversas esferas de acción, a las cuales busca integrar en una sola. Weber, como Rosenzweig, pondrá el dedo en la llaga del idealismo, de la "cultura": la muerte es la auténtica cruz que el "hombre cultivado", a sabiendas de su improbable éxito, ha rehusado tomar sobre si $^{32}$.

Por mucho que se la ignore, la muerte está ahí reclamando el reconocimiento de su insuperabilidad. Pretender que, desde la perspectiva del Uno-Todo (Ein-All), la muerte es Nada: he ahí la "mentira piadosa" de la filosofía, que genera "la ilusión de la carencia de presupuestos" $"$. El anhypotheton platónico se funda, pues, en la pretensión de silenciar lo que en rigor jamás podrá silenciarse: el grito del hombre que muere, grito que excede, que no se conforma al Todo. El Todo ya no es lo verdadero, sino precisamente lo que cercena la realidad y eo ipso la verdad. Pues el axioma del Nuevo Pensamiento es el de la filosofía positiva schellingiana: hay un Prius del pensamiento, del cual este depende y no viceversa. Y, como en Schelling, tal dependencia esencial comporta una muy audaz noción de creación que subvierte los más sólidos principios de toda ontoteología:

"La verdad no corrobora la realidad, sino que la realidad hace verdadera a la verdad, la guarda. La esencia del mundo es esta preservación (Bewahrung) - que no probación (Bewährung) - de la verdad. Hacia «fuera», pues, el mundo carece de la protección que la verdad le había garantizado al Todo desde Parménides a Hegel. [...] Tiene que exponerse a cuanto pueda acontecer aunque ello sea...su creación" 34 .

Dios ya no es el ipsum esse subsistens, sino el Señor del ser. Sin este desafío schellingiano toda la revolución filosófica posthegeliana permanece ininteligible. Esta destrucción de la ontología, que todo un Martin Heidegger podría haber visto anticipada en Rosenzweig, parte de la inscripción en la temporalidad radical y ori-

\footnotetext{
${ }^{32}$ Para todo esto, consúltense las últimas páginas de la Zwischenbetrachtung weberiana ("Excurso. Teoría de los estadios y direcciones del rechazo religioso del mundo" en Ensayos sobre sociología de la religión $v$. I, op. cit., pp. 558-559).

${ }^{33}$ Rosenzweig, F., La estrella de la redención, op. cit., p. 45.

${ }^{34}$ Op. cit., p. 55.
} 
ginaria del lenguaje para abrirse, desde ella, a la existencia, a la experiencia infundada, anárquica, de estar a merced del otro, de no ser sino por el otro. Ex-sistencia es estar fuera, no poder ser al modo cartesiano, desde sí mismo. Y tal aperturidad se constituye en el auténtico milagro del lenguaje, para cuya comprensión es menester situarse, nos dice Rosenzweig, en el angosto puente tendido entre Creación y Revelación.

Maticemos ya una cuestión, para ahorrarnos eventuales malentendidos: entender la Estrella como un libro judío o, peor aún, "religioso", sería tergiversar por completo el sentido de lo que aquí estamos explicando. Más adelante veremos, al intentar conectar a Rosenzweig con la construcción histórica weberiana, que el principal objeto que persigue la Estrella es la elaboración de un "sistema de filosofía"35, cuyo método nace, Rosenzweig no lo niega, de una cierta experiencia de lo judío y de la necesidad de su recuperación ${ }^{36}$, pero cuyo objeto no dista demasiado de aquella "ciencia de la realidad" en que se afanó Weber. Tal ciencia será en Rosenzweig, ya lo hemos insinuado, esotérica. Obviamente en Weber no hay interés alguno por narrar el mundo de la Revelación con su lenguaje interno, pero a Rosenzweig eso le importó bien poco. Se trataba, como le dejó escrito a su madre tras haber leído los estudios weberianos sobre judaísmo, de "tener los cinco sentidos abiertos" $"$ " El buen Dios queda al margen.

No obstante, como empezábamos a atisbar, los dos fenómenos primordiales en que ancla el Nuevo Pensamiento, tiempo y lenguaje, presuponen la dimensión de la creaturalidad. La interpretación del paganismo nos suministra múltiples claves a este respecto. Por un lado, esclarece, en su contraste, la cuestión del "judaísmo metódico" articulado en torno al prefijo meta- como signo del resquebrajamiento del Todo; por otro, guía hacia lo que será el núcleo del presente apartado, la dialéctica judeo-cristiana. Advirtamos que no se trata en absoluto de una teoría histórica del paganismo, sino de su caracterización sistemática. Lo que Rosenzweig llama el Antemundo sería el estadio en que los elementos Dios, Mundo y Hombre están

\footnotetext{
${ }^{35}$ Rosenzweig, F., El nuevo pensamiento, op. cit., p. 45.

${ }^{36} \mathrm{Al}$ respecto puede consultarse, siempre con provecho, la introducción de Miguel García-Baró a su traducción de La estrella, "Introducción. La figura de la Estrella. Una perspectiva global para la lectura de Rosenzweig”, en La estrella de la redención, op. cit., pp. 12-18.

${ }^{37}$ En cierto modo, esa carta del 15 de agosto de 1921 es el origen de toda mi propuesta de trabajo, cuya justificación se procurará desgranar en lo que resta. Es ella, pues, la que me autoriza a estudiar conjuntamente a estos dos autores. Tras comunicarle a su madre la lectura weberiana, lamentándose de no haberla realizado antes de la redacción de la Estrella, le confiesa que encuentra en Weber, expresado históricamente, exactamente lo mismo que él ha intentado filosóficamente. Esta afinidad, apunta Rosenzweig, tal vez Weber no podría corroborarla, lo cual en su opinión no atenúa en absoluto su efectividad. Las últimas palabras son, en este sentido, sumamente elocuentes: "Es ist wieder ein Beweis, dass es gar nicht darauf ankommt, ob man an den "lieben Gott" "glaubt", sondern nur ob man seine fünf Sinne aufschliesst und die Tatsachen sieht, - auf die Gefahr hin, dass sogar der liebe Gott darunter vorkommt" (Gesammelte Schriften 1. Briefe und Tagebücher, 2.Band, Dordrecht, Martinus Nijhoff, 1979, p. 717).
} 
enrigidecidos en su recíproco aislamiento. Grecia y su cosmos plástico serían el paradigma perfecto, y por eso surge en suelo griego la filosofía del Todo que se prolonga hasta Hegel. La lógica, como hemos mencionado, es la figura apropiada a este Todo que se definía por la exclusión de la Nada, de la muerte. La constatación del carácter metalógico de la facticidad del mundo conduce al resquebrajamiento de la unidad lógica de ser y pensar sobre la que se asienta el firme cosmos griego. La aprehensión por el Logos unifica, reúne (Versammlung, traducía Heidegger) con pulcritud algebraica la totalidad de lo real. Y tal reunificación ostenta irremisiblemente el signo de lo ya acabado. Así, la Creación, para ser siquiera concebible, requiere una retrospección desde la Revelación. Antes de la Revelación a lo único que se puede llegar es a la teoría plotiniana de la Emanación, cuya pervivencia en Hegel ya hemos discutido de la mano de Weber. Sólo la Revelación (que es siempre "segunda" revelación, esto es, posterior a la creación) hace que los elementos antemundanos salten de su quicio, a la manera de ese tiempo que Hamlet nos describe out of joint, y empiecen a relacionarse unos con otros, manifestando respectivamente su irreductible estar-ahí, la declosión de su clausura plástica. Es por ello que Rosenzweig protesta contra la asunción de la Creación como una explicación más "consistente" del problema científico del mundo. Esto sucede cuando se quiere, impacientemente, aplicar el idealismo a categorías que provienen del ámbito de la Revelación:

\begin{abstract}
"Mientras que el idealismo, pues, llevado por su sentimiento de tener que resolver aquí, por decirlo así, aquí mismo y ahora mismo, el enigma del mundo, dado que no puede reconocer la vigencia de nada exterior al mundo y al saber, tiene que poner en relación, a cualquier precio, los elementos Mundo y Saber, Sujeto y Objeto, y por ello mismo, está obligado a conservar los símbolos matemáticos, nosotros, en cambio, nos vemos aquí libres de tales símbolos"38.
\end{abstract}

La simbólica matemática, cuya univocidad vehicula la pretensión totalizante del idealismo, ha de abrirse a la experiencia gramatical de la Palabra, sólo desde la cual se puede tomar conciencia de la catástrofe del enclaustramiento idealista de la razón y de su paralizante pérdida de la facticidad. Recuperarla sólo es posible mediante la apertura de la razón a lo que se nos da desde fuera y hacemos nuestro, esto es, mediante la experiencia. Experiencia transida de raíz por el lenguaje, "la matemática verdaderamente superior" que, posicionándonos en un punto singular intransferible (la palabra proferida es siempre única, distinta cada vez), nos hace entrever "el curso entero de la ruta del milagro en que creemos" 39 . Sólo en la ruta, lenta y laboriosa, que traza la Redención se puede divisar lo que el Presente idealista rechaza de sí. He

\footnotetext{
${ }^{38}$ Op. cit., p. 184.

${ }^{39}$ Ibidem, p. 195.
} 
ahí por qué en el mismísimo Libro de la Creación está escrito que Dios, en el sexto día, dijo que lo entonces creado era, no bueno, sino muy bueno. Rosenzweig recoge, lleno de veneración, la enseñanza rabínica del Midrash Bereshit Rabbá: ese muy no es sino la muerte.

\section{La Revelación de la Estrella: el Fuego y los Rayos}

En unas pocas páginas he procurado, un tanto atropelladamente, delimitar algo así como el "discurso del método" del nuevo pensamiento. Ensayaré ahora, no con menor precipitación, la empresa final del trabajo: conectar la dialéctica judeocristiana descrita en la tercera parte de la Estrella con ciertos aspectos de la lectura weberiana del judaísmo anteriormente expuesta. Avanzo ya la clave que me ha orientado en todo momento: lo que Weber tematizó como una sociología del proceso de racionalización, para Rosenzweig, filosóficamente, sólo se entiende desde el centro de la Revelación. Es sólo la Revelación, esa "inversión" retroactiva de la topología elemental, la que posibilita la "tensión hacia el mundo" en la que desembocaba el análisis weberiano.

Pero vayamos por orden. La Revelación es, nos dice Rosenzweig en un primer momento, lo que permite definir el "lugar del paganismo", entendiendo por este, como dijimos, el ámbito antemundano de lo elemental. Allí los dioses no están en modo alguno "ocultos", sino, antes bien, perfectamente manifiestos, claramente visibles. En este sentido, la Revelación es inauguralmente pura negación de la teofanía mítica:

\footnotetext{
"Hay que suponer que la Revelación, al afirmar que no puede conocer la facticidad elemental de Dios y tildar a tal Dios de oculto, aspira a una facticidad que, en vez de ser la de ese Dios, sea la que le es adecuada: una que no está fundada en los elementos, sino en la ruta única de la realidad una; una facticidad que está elevada, más allá de todo quizá, a la altura de la seguridad absoluta"40.
}

Tal seguridad a la que arriba la Revelación no la sustenta ningún orden inmutable, sino precisamente un acontecimiento, sucedido justo en este instante y no antes ni después. Una cierta experiencia del tiempo, pues, "y nada más". La Revelación no añade nada, ni revela propiamente nada; tan sólo saca de su letargo intemporal a los elementos estáticos del cosmos mítico y los pone en movimiento:

"Debe, pues, tratarse de una revelación que no ponga nada, que no cree de sí nada sacándolo al vacío. [...] El llegar a ser patente que ahora estamos buscando tiene que ser tal que sea por completo esencialmente Revelación y nada más. Pero esto

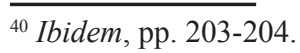


significa que no le es lícito ser sino el abrirse de algo cerrado; la autonegación por una pura palabra de una esencia meramente muda; la autonegación por un instante móvil de una perpetuidad que descansa en la calma. En el brillo de tal instante habita la fuerza de transformar el ser creado al que este brillo alcanza, de manera que, de cosa creada, pase a ser testimonio de un revelar que ha tenido lugar" 41 .

La esencia meramente muda despierta a la palabra por el puro imperativo, en primera persona, del amor. El Ámame divino es "la palabra-raíz de todo el diálogo de la Revelación" ${ }^{42}$. Sólo un amor tal, incondicional y, sobre todo, inmerecido, suscita en el alma amada una experiencia nueva, infinitamente más profunda que la vergüenza: el pecado, que no consiste sino en el haber estado hundida en el "ensimismamiento" antes de la "alteración", de la irrupción del otro. Sólo el pecador puede entregarse enteramente al amor, más allá de toda compensación, pues se ha transfigurado en el vértigo de la asimetría radical. Es el amante quien, inescrutablemente, da el primer paso. A la amada sólo le cabe responder, "pues el amor del amante carece de razones, por contraste con el amor de la amada, que tiene su razón y su fundamento en aquél"³. En un giro casi kierkegaardianamente tortuoso, Rosenzweig enlaza de modo esencial la condición de pecador con la posibilidad de responder al amor del amante. Tal entrelazamiento hace que la expresión del amor no se satisfaga con la confesión de los pecados pasados, sino que exige la declaración sincera de la pecaminosidad presente, sólo posible desde el presentimiento (¡no buscado!) del perdón divino, esto es, desde el saberse amada de Dios.

La ratificación de este ser interpelada el alma es obrada por Dios mediante una adecuación a la "forma del mundo". Al dirigírsele al alma el Eres mía se consolidan sus vínculos con el mundo, se fortalece el fundamento histórico del milagro de la Revelación, una vez gozada la dicha del encuentro. Así, puede Rosenzweig escribir del alma:

\begin{abstract}
"Ahora sí puede tranquilamente abrir los ojos y mirar en torno el mundo de las cosas. No hay cosa que pueda separarla de Dios, porque al mirar el mundo de las cosas está viendo en la facticidad irrevocable de un acontecimiento histórico el fundamento histórico de su fe. El alma puede dedicarse al mundo con los ojos abiertos y sin andar soñando, que siempre permanecerá en la cercanía de Dios"44.
\end{abstract}

\footnotetext{
${ }^{41}$ Ibidem, p. 206.

${ }^{42}$ Ibidem, p. 223.

${ }^{43}$ Ibidem, p. 226. Pueden evocarse aquí los dos pilares del estudio weberiano: el carácter asimétrico de la Alianza y la idea de pecado que de él se deriva.

${ }^{44}$ Ibidem, p. 230.
} 
Volvemos a transitar, pues, el camino indicado por Weber: del pecado al mundo. El ingreso en el mundo de la Revelación trajo consigo, consecuentemente, la consideración del cosmos plástico como un mundo "encantado". De este modo se desvaneció lo sólido, lo "hogareño" del cosmos platónico-aristotélico, el cual, desde sí mismo, no era "mágico", sino íntimo, perfectamente estable y firme. Deviene mundo encantado sólo mediante el concepto del mundo como criatura, sólo accesible desde el imperativo heterónomo del amor pronunciado por la Revelación, y que es la verdadera condición de posibilidad de esa "nueva ciencia del mundo" que, a partir del siglo XVII, pasa ella misma a configurar el propio mundo ${ }^{45}$.

Indagaremos ahora, para concluir, el modo en que Rosenzweig circunscribe el ingreso en la Revelación a las coordenadas judeocristianas. Si hasta ahora la excentricidad gramatical se nos ha mostrado como la llave que nos abre a un pensamiento "en la forma del mundo", Rosenzweig ensayará hacia el final de la Estrella un nuevo y decisivo desplazamiento: de la gramática a la liturgia, pues, si bien el mundo no puede estar sin la palabra, el "supramundo" redimido y el gesto litúrgico que lo anticipa se hallan en irreconciliable desajuste, más allá de toda simultaneidad. Por ello Rosenzweig se vale de la Figura de la Estrella, de esa luz que "no se da ni enajena a sí misma, como el lenguaje, cuando se exterioriza, sino que es visible permaneciendo por completo en sí misma" ${ }^{46}$. El carácter litúrgico de la anticipación presente de la Redención por venir es la encrucijada de los tiempos que remite, ya desde la historia del mundo, a lo que la excede. Y ello sólo en la esperanza y en el presentimiento, sin dejarse traer a presencia, pues la luz no se agota en su visibilidad.

Desde una tal filosofía de la liturgia y de su calendario aborda Rosenzweig la cuestión judeocristiana. Se ha querido ver en la interpretación rosenzweiguiana un rescoldo de hegelianismo. Puede ser, pero, desde luego, nunca llegó a prender. En efecto, hay que reconocer que el fuego del judaísmo, aliméntandose de sí mismo, necesita de su proyección externa ("los Rayos") en forma de cristianismo, del mismo modo que este absorbe toda su enjundia vital de aquel centro incandescente. Ambos, forman el arco de la ruta de la Estrella, mas desde una "nueva" dialéctica, por así decirlo, sin síntesis. El $Y$ es el signo más palmario de esta nueva dialéctica, en que los términos no pueden subsistir el uno sin el otro, pero sin llegar nunca pro statu isto a la reunificación, al ecumenismo conciliador que muchos han querido ver en Rosenzweig, para quien, por el contrario, la "mala" infinitud era, en realidad, la buena.

Introduzco el tema, como in medias res, con una cita abrupta y apretada:

\footnotetext{
${ }^{45}$ Cf. ibidem, p. 269.

${ }^{46}$ Ibidem, p. 352.
} 
"Entre los pueblos del mundo se ha producido una discordia desde que ha venido a ellos la potencia supranacional del cristianismo. Desde entonces hay en todas partes un Sigfrido que lucha con esta extraña figura, que ya le es sospechosa por su aspecto, del hombre crucificado[...]. Sólo para el judío no hay disensión entre la más alta imagen puesta ante su alma y el pueblo al que su vida le lleva. Sólo él posee la unidad del mito que por el cristianismo perdieron y tenían que perder los pueblos del mundo. Tenían que perderla, porque el mito que ellos poseían era un mito pagano, que los apartaba de Dios y del prójimo mientras los sumía en sí mismos. Al llevarlo a su pueblo, su mito lleva al judío, al mismo tiempo, bajo el rostro de su Dios, que es también el Dios de los pueblos"47.

Cuando el cosmos plástico del paganismo hubo adquirido su forma política última bajo Augusto, se produjo, en la historia, una inversión afín a aquella que conocimos en la teoría de la Revelación: todo se pone del revés y los pueblos se ven constreñidos a dirimir si se orientan mirando al futuro hacia el que apunta el cristianismo o permanecen aferrados a su respectivo pasado mítico fundacional. Para Rosenzweig, me atrevería a decir, la entera historia europea no sería sino la consecuencia del carácter jánico del instante en que los pueblos comienzan a cristianizarse. Las raíces oscuras de la identidad pagana, en conjunción con la apropiación de la noción bíblica de elección, propiciarán el surgimiento de algo que para Rosenzweig simplemente no existía en el mundo pre-cristiano: la guerra de religión. En su sentido estrictamente veterotestamentario, la "guerra de religión" es aquella en la que va envuelta alguna acción necesaria por parte de Dios, diferenciándose, por tanto, nítidamente de la guerra tout court. Los pueblos cristianos, destinados a convertirse en los únicos que haya sobre la tierra, han olvidado tal distinción convirtiendo toda guerra en guerra religiosa, mientras que para el judío sin tierra ya ninguna lo es.

De aquí hay tan sólo un paso hasta lo que, a mi entender, constituye el meollo de esta tercera y última parte de La estrella: la cristianidad de la historia y la metahistoricidad del judaísmo. Para Rosenzweig el pueblo judío es el pueblo eterno porque, al abandonar la forma estatal, se concentra única y exclusivamente sobre sí mismo en la eternidad anticipatoria de la liturgia. De este modo, genera la única excepción a la temporalidad bélica de los pueblos. Vemos, pues, cómo se retoman aquí temas fundamentales de Hegel y el Estado. El Estado, con su catecóntica ambigüedad perenne (instaura derecho a través de la violencia), es el intento incensante y siempre fallido, por parte de los pueblos, de "detener" (hablamos, por ello, de "épocas") el flujo irreversible del tiempo, o, en expresión de Rosenzweig, "de dar a los pueblos eternidad en el tiempo" 48 . El tiempo cristiano quiere ahora lo que sólo podrá ser al final del trayecto en que su propia existencia consiste. La

\footnotetext{
${ }^{47}$ Ibidem, p. 390.

${ }^{48}$ Ibidem, pp. 393-394.
} 
guerra y la revolución serían así signos de una impaciencia, olvido de que se está todavía nel mezzo del cammin.

En realidad, de la teoría rosenzweigiana del cristianismo se desprende, si bien que un tanto ambiguamente, que los nacionalismos modernos fueron un duro obstáculo, interno y surgido de él mismo, para el propio cristianismo. La ontoteología de la nación trabajaba en dirección exactamente inversa a lo que, para Rosenzweig, nada harnackianamente, constituye "la esencia del cristianismo", esto es, ser "lo sin fronteras, lo que hace saltar siempre todas las fronteras" 49 . El cristianismo, la pura "expansión hacia fuera", tuvo que surgir por fuerza en ese mundo jurídicamente unificado que fue el imperium del César. El "otoño de la Edad Media" vendría motivado por la transferencia de la voluntad imperial a la pluralidad de los pueblos. Mas la época de los Estados, advierte Rosenzweig, como fase del proceso cristiano que es, toca a su fin, ya que "cuando se haya desgastado por el mutuo roce esta voluntad de imperio en los pueblos, tomará una figura nueva"50.

La erosión estatal es indicio de una nueva era cristiana. En la eclesiología de la Estrella, de raíz joaquinita y schellinguiana, se la llama la era "joánica". No podemos entrar ahora en el tema de las edades de la Iglesia, pero sí nos interesa, para concluir, ponerlo al menos en conexión con el Finale escatológico con que concluye Rosenzweig su obra. Dado que la historia del mundo no es sino la historia de la expansión cristiana, desde el cristianismo joánico, que es el último, el que conjuga la exterioridad petrina con la interioridad paulina, tiene que poder plantearse la cuestión de su consumación final. Entramos así en lo que Rosenzweig articula como una teoría de la verdad y de la eternidad. Nadie puede, mientras viva sobre la tierra, arrogarse la posesión exclusiva de la verdad. La verdad es sinfónica; es, como se dice en una carta a Rosenstock, el "diálogo de muchos monólogos". Su obra (su preservación, que no verificación) requiere paciencia y humildad, confianza. La premura y la precipitación la entorpecen más que la aceleran. Y la historia humana no parece otra cosa que la concatenación ingente de los innúmeros afanes por ostentar la verdad "completa".

"Pero nosotros sabemos que la esencia de la verdad es estar partida, y que una verdad que no es la porción de nadie no es verdad ninguna. La misma verdad entera es sólo verdad porque es la parte de Dios. No va, pues, en detrimento de la verdad ni de nosotros que la verdad sólo sea nuestra porción, sólo se nos haya concedido como tal. La visión inmediata de la verdad entera sólo se le da al que la ve en Dios. Pero esta visión es de más allá de la vida".

\footnotetext{
${ }^{49}$ Ibidem, p. 411.

${ }^{50}$ Ibidem, p. 416.
} 
Podrá parecer extraño, pero creo que este es un párrafo weberiano, pues, si Weber nos decía (en realidad, por mucho que se diga, refutando todo relativismo) que las distintas esferas tienen su propia legitimidad, Rosenzweig nos lo repite desde la Revelación. Tanto el fuego interno como su irradiación visible, o, dicho según el versículo joánico, tanto la Vida como el Camino forman parte de la Verdad. Ante una Verdad tal, escribe Rosenzweig en las últimas páginas, se resquebrajan los Ismos, auténticos ídolos de nuestro tiempo. Tal vez Rosenzweig y Weber, con su ejemplar labor de lucidez, genio y rigor, no quisieron sino contribuir a conjurarlos. 